\title{
Diode laser photocoagulation to the vascular retina for progressively advancing retinopathy of prematurity
}

\author{
Michael O’Keefe, John Burke, Kais Algawi, Michael Goggin
}

\begin{abstract}
Aims-To estimate the effectiveness of diode laser photocoagulation of the retina posterior to the ridge in eyes with retinopathy of prematurity (ROP).

Methods-Diode laser photocoagulation was applied posterior to the fibrovascular ridge in stage 4a ROP in six eyes of four infants and in advancing stage $3+$ in two eyes of one infant. Seven eyes had previously been unsuccessfully treated with diode laser photocoagulation anterior to the ridge.

Results-Six eyes of four children had total regression, two eyes of two children had flat maculae with residual peripheral tractional detachment and maintained vision.

Conclusion-These preliminary results indicate that diode laser photocoagulation posterior to the ridge may be a useful treatment in late stage 3 and stage $4 A$ ROP following failed laser treatment to the avascular retina in threshold stage 3 disease.

(Br f Ophthalmol 1995; 79: 1012-1014)
\end{abstract}

Retinal cryotherapy and laser photocoagulation are successful methods of treating threshold retinopathy of prematurity (ROP) when used to ablate the avascular retina anterior to the fibrovascular ridge. ${ }^{1-8}$ The timely recognition of threshold disease is important because of the short window of opportunity ${ }^{9}$ during which therapy is effective. Despite treatment that is adequately timed and applied, a proportion of eyes advance to stage 4 and stage 5 disease. ${ }^{1-5}$ In this study, we describe diode laser photocoagulation of the retina posterior to the ridge in eyes with progressively advancing stage $3+$ and stage $4 a$ ROP following initial extensive diode laser application to the avascular anterior retina.

Ophthalmology, The

Children's Hospital,

Dublin, Ireland

M O'Keefe

K Algawi

M Goggin

Department of

Ophthalmology, Royal

Hallamshire Hospital,

Sheffield

J Burke

Correspondence to: Mr Michael O'Keefe Department of

Ophthalmology, The

Children's Hospital, Temple Street, Dublin 1, Ireland.

Accepted for publication

10 August 1995 to $1000 \mathrm{~g}$ ). Laser treatment of the avascular retina anterior to the ridge was performed initially on seven of the eight eyes. The first laser intervention was carried out when the disease progressed to 'threshold' level (stage
$3+$, zone 2,5 contiguous or 8 cumulative clock hours or more severe). In the eighth eye, the disease had progressed to stage 4 a for 5 contiguous clock hours in zone 2 by the time the first screening examination was due, according to the screening protocol in use at that time. The fellow eye in this infant was already at stage 5 at this examination. Further laser was applied to skip areas so that there was complete or almost complete laser application to the avascular retina. Despite this, the disease progressed to stage $4 \mathrm{a}$ in five of the seven eyes and persistent progression of stage $3+$ disease in the other two with vitreoretinal traction and prominent plus disease. Retinal diode laser photocoagulation was then applied to these eyes posterior to the ridge in an attempt to half disease progression and limit tractional detachment. Because of the severe and aggressive nature of the stage $4 \mathrm{a}$ disease in the eighth eye (which was already an only eye), the same rationale for posterior treatment was applied, in the absence of previous laser photocoagulation. In all cases with stage $4 \mathrm{a}$ disease, treatment extended to about 1 disc diameter nasal to the optic disc, 3 disc diameters temporal to fovea, and outside the temporal vascular arcade superiorly and inferiorly. In the two eyes with non-regressing stage 3 disease, the treatment was confined to the vascular retina just posterior to the ridge in the inferotemporal quadrant in one eye and all down the temporal side in the other. The numbers of burns placed inside and outside the ridge in each eye treated in this manner appear in Table 1. The laser power used varied between 300 and $100 \mathrm{~mW}$ and the duration between $200 \mathrm{~ms}$ and $500 \mathrm{~ms}$. Increased power and duration were required to elicit a visible 'burn' in areas where subretinal fluid was present.

\section{Results}

Four eyes of two children (eyes 1 to 4 , in Table 1), not having responded to complete or almost complete treatment, anterior to the fibrovascular ridge, over 2 weeks, progressed to stage 4 disease with peripheral tractional retinal detachment. About 1 week following treatment of the retina posterior to the ridge, the tractional detachment started to flatten. At the last examination, all four retinas were reattached. Both eyes of a third child (eyes 5 and 6 , in Table 1) had non-regressing stage 3+ disease despite complete ablation of the avascular retina, carried out in two treatment sessions over a 3 week period. These eyes received limited laser therapy to the vascular 
Table 1 Siting and quantity of laser burns, retinal and visual outcome

\begin{tabular}{|c|c|c|c|c|c|c|}
\hline \multirow{2}{*}{$\begin{array}{l}\text { Eye } \\
\text { No }\end{array}$} & \multirow[b]{2}{*}{ Stage } & \multirow[b]{2}{*}{ Retinal zone } & \multicolumn{2}{|c|}{ No of burns } & \multirow[b]{2}{*}{ Retinal outcome } & \multirow[b]{2}{*}{ Visual outcome } \\
\hline & & & $A R$ & $V R$ & & \\
\hline $\begin{array}{l}1 \\
2 \\
3 \\
4 \\
5 \\
6 \\
7 \\
8\end{array}$ & $\begin{array}{l}4 \mathrm{a} \\
4 \mathrm{a} \\
4 \mathrm{a} \\
4 \mathrm{a} \\
4 \mathrm{a} \\
3+ \\
4 \mathrm{a} \\
4 \mathrm{a}\end{array}$ & $\begin{array}{l}\text { Posterior zone } 2 \\
\text { Posterior zone } 2 \\
\text { Posterior zone } 2 \\
\text { Posterior zone } 2 \\
\text { Posterior zone } 2 \\
\text { Posterior zone } 2 \\
\text { Mid zone } 2 \\
\text { Mid zone } 2\end{array}$ & $\begin{array}{r}1020 \\
1049 \\
691 \\
726 \\
1842 \\
2441 \\
636 \\
600\end{array}$ & $\begin{array}{l}218 \\
272 \\
219 \\
408 \\
100 \\
500 \\
568 \\
400\end{array}$ & $\begin{array}{l}\text { Flat } \\
\text { Flat } \\
\text { Flat } \\
\text { Flat } \\
\text { Flat } \\
\text { Flat } \\
\text { Peripheral } R D \text {, macula flat } \\
\text { Peripheral } R D \text {, extrafoveal macular traction }\end{array}$ & $\begin{array}{l}\text { CSM } \\
\text { CSM } \\
\text { CSM } \\
\text { CSM } \\
\text { Fixes, intermittent follows } \\
\text { Fixes, intermittent follows } \\
12 \text { cpd FCP } \\
1.6 \text { cpd FCP }\end{array}$ \\
\hline
\end{tabular}

Stage = stage of disease at time of treatment of vascular retina, $A R=$ avascular retina, $V R=$ vascular retina, $C S M=c e n t r a l$ steady and maintained fixation, $\mathrm{RD}=$ retinal detachment, $\mathrm{FCP}=$ forced choice preferential looking.

retina (in the inferotemporal quadrant, just behind the ridge in eye 5 and in the same area of the whole temporal side in eye 6). One eye in a fourth infant progressed to total retinal detachment having received 683 burns applied in the conventional manner, anterior to the ridge, while the fellow eye in this case (eye 7 , Table 1) which received laser posterior to the ridge after conventional anterior treatment, has a flat posterior pole and a peripheral detachment in the temporal retina. The eighth eye (eye 8 , Table 1 ) received laser anterior to the ridge and to the posterior retina at the first and only treatment session (the fellow retina being already totally detached at the first screening examination). There are macular pigmentary changes and tractional detachment of the macular retina in the region of the upper temporal arcade. Heavy scarring with hyperpigmentation was noticed at the areas treated in all eyes described.

At last examination, all four eyes in the two children with stage 4 disease had central, steady, and maintained fixation. Both eyes of the third child (eyes 5 and 6 , in Table 1) at the review at 3 months' postmenstrual age were fixing and following. One eye of the fourth child (eye 7 , in Table 1) had a vision of 12 cycles per degree (cpd) on preferential looking at $38 \mathrm{~cm}$ at last review aged 3 years. The vision of the eighth eye (eye 8 , in Table 1 ) was 1.6 cpd when last recorded at age 2 years.

\section{Discussion}

Retinopathy of prematurity is a leading cause of blindness in the perinatal period. ${ }^{10}$ The Cryotherapy for Retinopathy of Prematurity Co-operative Group established a specific disease severity that, though not based on research data, has served as a uniform treatment point. ${ }^{1-3}$ The Cryo-ROP studies demonstrated the effectiveness of cryotherapy in reducing the risk of an unfavourable outcome from threshold ROP. Photocoagulation was the first surgical approach to treatment, but it took the introduction of a portable delivery system for laser energy to make treatment in the neonatal intensive care unit possible. The specific advantages of this modality are the ability to carry out treatment without general anaesthesia, ${ }^{5}$ the facility to respond rapidly to advancing disease and thus titrate the 'dose' of treatment to the individual eye, avoidance of lesions to the sclera and the external eye surface and, perhaps, the minimisation of myopia in later life. ${ }^{11}$
Despite the success of cryotherapy and laser photocoagulation, a significant percentage of eyes progress to retinal detachment. ${ }^{1-5}$ In these patients, even skilful vitreoretinal surgery, with anatomical success, offers a poor visual prognosis. ${ }^{12}$ Currently established practice is to apply laser, or cryotherapy, to the avascular retina anterior to the ridge when threshold disease occurs. The effect of this is possibly twofold. It reduces or eliminates the release of 'vasogenic factors' which are thought to stimulate abnormal vessel growth, and it encourages chorioretinal adhesions which may contribute to the successful outcome. No vasogenic agent has been isolated although we assume its presence. Given that the chorioretinal diode laser burn is relatively deep, part of its therapeutic effect may be the creation of focal chorioretinal adhesions in the treated areas. ${ }^{13}$ Hindle has advocated treatment of the fibrovascular ridge directly. ${ }^{14}$ We have been reluctant to do this because it has been our experience and that of others, that, where laser was inadvertently directed to the ridge, intraretinal and vitreous haemorrhage often ensued from the delicate and abnormally friable new vessels. Treatment of the vascular retina after initially treating the avascular retina is a new approach. We have performed this in cases where the disease progressed to early stage $4 a$ in five eyes, despite complete photocoagulation of the avascular retina anterior to the ridge; where stage $4 \mathrm{a}$ disease was present at the initial examination (one eye); and with advancing stage $3+$ disease despite similarly complete photocoagulation of the anterior avascular retina (two eyes). Technically, treatment posterior to the ridge, in zone 2 in most cases, with the indirect laser is generally not difficult. In order to apply cryotherapy to the same area, an open surgical approach, with general anaesthesia, would be necessary. We have experienced differences with the method of laser application in that one generally requires greater laser power and/or burn duration to elicit a visible reaction particularly in areas of shallow retinal elevation.

Our results are encouraging in that four eyes, with stage 4 a disease, regressed with this therapy. Two eyes had progressive stage $3+$ disease halted with limited ablation of the vascular retina and two further eyes have flat maculae but significant peripheral tractional changes. All of the eyes have some visual function but all have extensive retinal pigment epithelial changes in the treated areas which may well impact on their visual fields.

Although the Cryo-ROP study therapeutic 
guidelines represent a large step forward in the control of ROP, it has only established that one form of treatment in one specific form of the disease is effective (avascular retinal cryoablation in threshold disease). Although anatomical success occurs with vitreoretinal surgery, ${ }^{15-17}$ the functional outcome is poor. ${ }^{12}$ We feel that treatment of the vascular retina in previously conventionally, but unsuccessfully treated avascular retina in advancing stage $3+$ and stage 4 a disease is successful in selected cases. The treatment of the vascular retina is new and radical and we recognise that the number of children treated is small, but the successful outcome merits further evaluation.

1 Cryotherapy for Retinopathy of Prematurity Cooperative Group. Multicenter trial of cryotherapy for retinopathy of prematurity: preliminary results. Arch Ophthalmol 1988; 106: 471-9.

2 Cryotherapy for Retinopathy of Prematurity Cooperative Group. Multicenter trial of cryotherapy for retinopathy of prematurity: three-month outcome. Arch Ophthalmol prematurity: three-mot

3 Cryotherapy for Retinopathy of Prematurity Cooperative Group. Multicenter trial of cryotherapy for retinopathy of prematurity: one-year outcome - structure and function. Arch Ophthalmol 1990; 108: 1408-16.

4 Robinson R, O'Keefe M. Cryotherapy for retinopathy of prematurity - a prospective study. Br f Ophthalmol 1992; 76: 289-91.

5 Goggin M, O'Keefe M. Diode laser for retinopathy of prematurity - early outcome. $B r \mathcal{F}$ Ophthalmol 1993; 77: 559-62.

6 Landers III MB, Toth CA, Seple HC, Morse LS. Treatment of retinopathy of prematurity with argon laser photocoagulation. Arch Ophthalmol 1992; 110: 44-7.

7 Preslan MW. Laser therapy for retinopathy of prematurity. f Pediatr Ophthalmol Strabismus 1993; 30: 80-3.

8 McNamara JA, Tasman W, Vander JF, Brown GC. Diode laser photocoagulation for retinopathy of prematurity. Preliminary results. Arch Ophthalmol 1992; 110: 1714-6.

9 Fielder AR. Cryotherapy of retinopathy of prematurity. In: Davidson SI, Jay B, eds. Recent advances in ophthalmology 8. London: Churchill Livingstone, 1992: 129-48.

10 Goggin M, O'Keefe $M$. Childhood blindness in the Republic of Ireland - a national survey. Br $₹$ Ophthalmol 1991; 75: 425-9.

11 Algawi K, Goggin M, O'Keefe M. Refractive outcome following diode laser versus cryotherapy for eyes with retinopathy of prematurity. $\mathrm{Br} \mathcal{F}$ Ophthalmol 1994; 78: retinopath

12 Quinn GE, Dobson V, Barr CC, Davis BR, Flynn JT, Palmer EA, et al. Visual acuity in infants after vitrectomy for severe retinopathy of prematurity. Ophthalmology 991; 98: 5-13.

13 Menchini U, Trabucchi G, Brancato R, Capellini A. Can diode laser $(810 \mathrm{~nm})$ effectively produce chorioretinal adhesion? Retina 1992; 12: 580-6.

14 Hindle NW. Critical mass retinopathy of prematurity: what is it and what can you do about it? Doc Ophthalmol 1990; 74: 253-62.

15 Zilis JD, deJuan E, Machemer R. Advanced retinopathy of prematurity. The anatomic and visual results of vitreous prematurity. The anatomic and visual resul
surgery. Ophthalmology 1990; 97: 821-6.

16 Trese MT. Visual results and prognostic factors for vision following surgery for stage $V$ retinopathy of prematurity. Ophthalmology 1986; 93: 574-9.

17 Sehber JH, Machemer R, Eliott D, Buckley EG, deJuan E, Martin DF. Long term visual results of children after initially successful vitrectomy for stage $\mathrm{V}$ retinopathy of prematurity. Ophthalmology 1995; 102: 199-204. 